\title{
The influence of digital marketing on recruitment effectiveness: a qualitative study
}

\author{
Dalvia Rodrigues and Luis F. Martinez \\ Nova School of Business and Economics, Universidade Nova de Lisboa, Lisbon, Portugal
}

Influence of digital marketing

\begin{abstract}
Purpose - The purpose of this paper is to unfold how different digital marketing tools and strategies influence recruitment effectiveness. More specifically, it focusses on understanding if, and how, information sources' credibility, content marketing, and organisational reputation influence candidates' decision to apply for a job in the Portuguese market.

Design/methodology/approach - A qualitative research, aligned with a content analysis, was conducted to focus on the insights from the 21 participants interviewed, to understand their thoughts and experiences regarding the subject.

Findings - The results show that digital marketing tools owned by the company are seen to be more credible and more relevant for the job application decision. LinkedIn is considered to be a more credible platform for advertising job openings than Facebook. In terms of content marketing, LinkedIn has a positive influence on candidates' decision, as well as companies' reputation.

Practical implications - This study provides practical implications which are useful for both HR and marketing managers, namely, the implementation of an integrated marketing communication strategy, the reinforcement of the company's website and LinkedIn page and a presence on universities' platforms, and also in terms of the information that content marketing should focus on.

Originality/value - This research paper incorporates marketing insights into a well-known HRM subject - recruitment, and thus adds further knowledge to the literature and prepares the ground for researchers who wish to explore this subject further.
\end{abstract}

Keywords Digital marketing, Brand relationships, Corporate reputation, Recruitment, Job advertisement

Paper type Research paper

\section{Introduction}

According to Judy (1999), the demand for highly skilled and well-educated employees is constant, which subsequently leads to an increase in the educational requirements for both specialists and entry-level employees. Elving, Westhoff, Meeusen, \& Schoonderbeek (2013)

(C) Dalvia Rodrigues and Luis F. Martinez. Published in European Journal of Management Studies. Published by Emerald Publishing Limited. This article is published under the Creative Commons Attribution (CC BY 4.0) licence. Anyone may reproduce, distribute, translate and create derivative works of this article (for both commercial and non-commercial purposes), subject to full attribution to the original publication and authors. The full terms of this licence maybe seen at http://creativecommons.org/licences/by/4.0/legalcode

This work was funded by Fundação para a Ciência e a Tecnologia (UID/ECO/00124/2013, UID/ ECO/00124/2019 and Social Sciences DataLab, LISBOA-01-0145-FEDER-022209), POR Lisboa (LISBOA-01-0145-FEDER-007722, LISBOA-01-0145-FEDER-022209) and POR Norte (LISBOA-010145-FEDER-022209). . 
EJMS

25,1

believe that this occurs because high-quality employees are fundamental to strengthen an organisation and have a positive influence on the organisation's reputation. A survey conducted by Capgemini Consulting in 2013 suggests that $70 \%$ of the organisations surveyed were concerned about the ability to recruit and retain talent in the current competitive marketplace, and not surprisingly, those which lag behind in adopting digital tools overlap with those which are most likely to confront challenges in recruiting and retaining talent (Spitzer, Vernet, Soderstrom, \& Nambiar, 2013). Furthermore, the ability to attract and retain employees is seen to be the most important determinant of an organisation's effectiveness by several authors (Breaugh, 2016; Chapman et al., 2005; Johnson, 2014; Rajan, 2015; Singh and Finn, 2003), and, according to Johnson (2014), companies should take a more proactive approach which involves recruitment, marketing and branding.

This study was conceived in this context and aims to contribute to furthering the HRM literature on the subject of recruitment effectiveness, by complementing it with marketing insights, especially with regards digital marketing. Because each market has its own specificities, the scope of the study is the Portuguese market, although it would be interesting to attempt to replicate this study in other countries, to assess the reliability of its methodology. The goal of the research is not only to add further knowledge to the literature, but also to provide a clear and practical understandings for managers.

\section{Recruitment: the definition and importance of information technology}

As mentioned above, hiring talented individuals is crucial, and can often be a difficult task. Recruitment can be defined as being the process which determines the number and type of applicants who apply for a certain job opportunity, which involves the advertising carried out from the moment that the company decides to hire, to when candidates apply, providing a pool of potential candidates, who then integrate in the selection process (Silvertzen et al., 2013). Recruitment is also known as the stage of attraction, whereby the process implies the development of a marketing strategy which is similar to the process which is used for products or services - namely, by setting the values, the selling proposition, the target audience and also the communication channels. According to Roberts (1997), the process of attracting candidates to apply for a job requires a balance, as managers need to achieve a sufficient pool of candidates - in terms of quantity and quality, to make good decisions.

To be able to recruit efficiently, Breaugh (2016) defends that HR managers must answer the following questions:

- Who to recruit?

- How to advertise the job position?

- What message needs to be communicated?

- Who are the recruiters?

There is no doubt that the way that the recruitment process is carried out influences the quality of the individuals that the company hires, their initial performance, the training required and, finally, the retention rate. Accordingly, if the recruitment process is carried out badly, then the company could end up hiring unqualified applicants, leading to a low performance and a lack of diversity, or even failing to attract applicants who would be a better fit (Breaugh, 2016; Elving et al., 2013; Johnson and Gueutal, 2011; Singh and Finn, 2003).

When it comes to the methods of advertising job openings, several authors (Breaugh, 2016; Johnson, 2014; Paolini \& Duguay, 2012; Singh \& Finn, 2003) defend that companies 
have a wide range of options, the most common and broadest ones being employees' referrals, the company's website, job boards, social networking sites (SNS) and college recruitment, among others. Singh and Finn (2003) go even further, by stating that, in the past, companies mostly used low-tech methods, such as newspaper advertisements and employees' referrals, but recently this is changing, mainly because of the substantial impact of information technology.

Spitzer et al. (2013) believe that digital marketing can revolutionise the way that HR processes are managed today. Technology - especially internet-based communication tools and social media - has already changed recruitment, as it reduces costs significantly and allows organisations to reach passive candidates more easily and enables them to be able to customise the recruitment message to different targeted groups, or even individuals - which ultimately prepares the ground for the development of relationships with prospective candidates through social networking sites (Breaugh, 2016; Caers \& Castelyns, 2011; Nikolaou, 2014; Richard, 2010; Singh and Finn, 2013; Spitzer et al., 2013). Furthermore, according to Johnson and Gueutal (2011), the so-called e-recruiting is a solution for reaching various organisational goals, such as the improvement of recruiting efficiency and cost reduction, as well as increasing the quality and quantity of applicants, while increasing the objectiveness and standardisation of practices and the convenience for applicants.

Companies use digital marketing to connect with their target, whilst at the same time building conversations and engagement through multiple touchpoints (Rajan, 2015), which enables them to leverage their employer branding and attraction and retain employees (Sivertzen, Nilsen, \& Olafsen, 2013). Cappelli (2001) defends that companies can promote themselves affordably and effectively by using the internet's power of spreading information through informal networking, which provides valuable content for the targeted groups, whilst collecting information on potential candidates at the same time. Rajan (2015) defends that it is increasingly relevant for HR managers to work with marketing managers to identify potential employees and to connect and engage with them and use this network to fulfill recruitment needs. Furthermore, the use of internet in recruitment is a win-win solution for both HR managers and job seekers alike - as candidates are searching for techsavvy employers, whilst companies aim to build a brand which is attractive and achieves visibility for its job postings, which requires the use of digital marketing (Johnson, 2014; Ladkin \& Buhalis, 2016; Paolini \& Duguay, 2012; Silvertzen et al., 2013).

\section{Digital marketing: definition, tools and strategies}

Kannan and Li (2017, p. 23) define digital marketing as being the process that uses digital technologies to "acquire customers and build customer preferences, promote brands, retain customers and increase sales". Accordingly, in the recruitment perspective, digital marketing enables a company to attract and engage potential candidates and to promote a two-way interaction, with the goal of retaining the most adequate candidate for its recruitment needs, using promotional techniques that go beyond the internet (Yasmin, Tasneem, \& Fatema, 2015). To improve employer attractiveness, organisations nowadays use these different forms of communication to reach candidates, connect with them, and build a positive employer image (Puncheva-Michelotti, Hudson, \& Jin, 2018).

Over the past years, a great deal of research has been focussed on digital marketing - as this is still a developing subject. One aspect that represents a different perspective regarding the current literature is the classification and division of digital marketing tools. For instance, Goldfarb (2014) defines digital marketing as "online advertising", and establishes three general categories, namely, search advertising, classified advertising and display advertising. Yasmin et al. (2015) define a set of the most important elements of digital
Influence of digital marketing 
EJMS

25,1

marketing, which consist of online advertising, email marketing, social media, text messaging, affiliate marketing, Search Engine Optimisation (SEO) and Pay per Click (PPC). Finally, Batra and Keller (2016) highlight six key online communication options, which include search advertisements, display advertisements, websites, email, social media and mobile phones.

As the focus of this study is recruitment, one cannot pass without mentioning those digital marketing elements which are specifically designed for recruitment, which, according to Johnson and Gueutal (2011), include the corporate recruiting website, general online job boards (e.g. Monster, HotJobs), industry-specific job boards and regional job boards. However, just using one of the elements presented above would represent a limited vision of what digital marketing entails, especially with regards the recruitment environment. Therefore, the optimal solution is to create a combination of the elements of the digital marketing tools which fit the recruitment overview, which is shown in Table 1.

In addition, the literature highlights a distinction between paid, earned and owned media, as these all have an influence on marketing strategy and are used together to ensure that the message is received multiple times and that it creates awareness, engagement and retention (Bonchek, 2014; DiStaso and Brown, 2015; Stephen and Galak, 2012). Several authors have contributed to the definition of these types of media (Baetzgen and Tropp, 2015; Boncheck, 2014; DiStaso and Brown, 2015; Stephen and Galak, 2012), stating that paid media is the category of media for which marketers have to contact a third-party organisation, which includes print, television and radio. Its main advantages are immediacy and scale, although these are being challenged by low credibility. Earned media includes all the media activity that the company does not generate directly, which results from public relations, press mentions and word-of-mouth (WOM). Earned media is also considered to be the most credible type of source, although it lacks control over the content, which can result in negative publicity. Finally, owned media represents all those channels which are under the direct control of the company, such as corporate websites and social media pages, which are made available without any media-buying costs. Table 2 shows how digital marketing tools can be distributed between paid, earned and owned media. In addition, social media can be seen to be both owned and earned media, because nowadays brands own their own channels and pages, although they do not control the WOM marketing which is created on these platforms (Bonchek, 2014; Stephen and Galak, 2012).

Content marketing is a digital marketing strategy which represents the process of creating and distributing relevant and valuable content which is not directly connected to the product, service or the job opening itself, with the objective to attract and engage the target audience (Baetzgen and Tropp, 2015; Kee and Yazdanifard, 2015; Rowley, 2008). According to Baltes (2015), content marketing has become a crucial aspect for successful digital marketing which enhances candidates' perception of credibility during the recruitment process, and thus positively influences their decision to apply for a job. Companies are beginning to realise that using digital tools in marketing is worthless if it they are not accompanied by a content marketing strategy which focusses on storytelling (Pulizzi, 2012). Companies can distribute content through their website, social media pages and email marketing, as well as other owned channels - creating value and using data to tailor the message, which represents an overall valued strategy in the present informationdriven context - where individuals are looking for evermore information to guide their decision-making process (Bonchek, 2014; Kee and Yazdanifard, 2015). Furthermore, companies are still struggling with the ability to create truly engaging content for candidates which delivers positive and meaningful results (Pulizzi, 2012). 


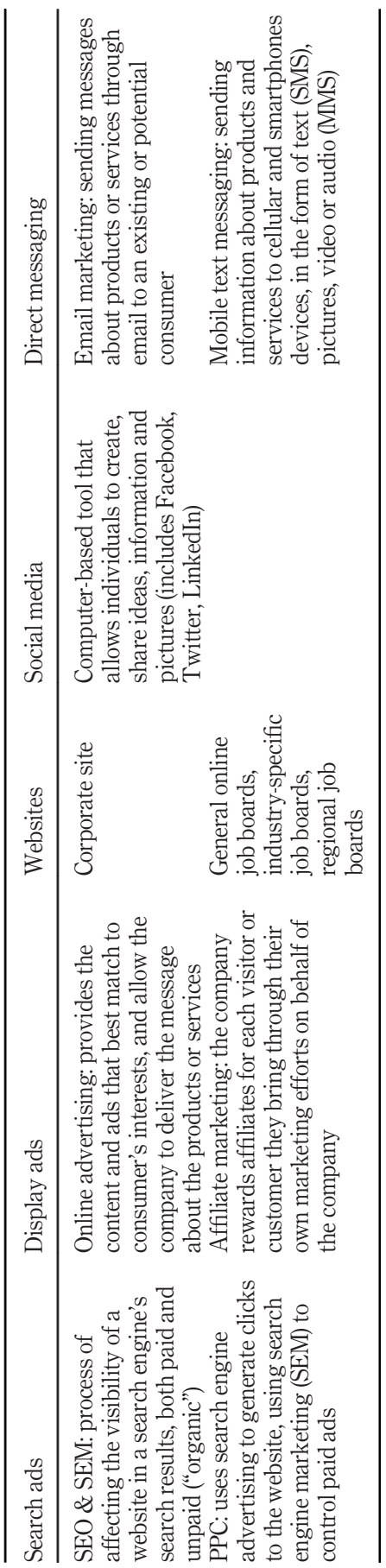

Influence of digital marketing

Table 1

Combined categorisation of digital marketing tools 


\section{EJMS \\ 25,1}

\begin{tabular}{ll}
$\begin{array}{l}\text { Paid media } \\
\text { SEO and SEM }\end{array}$ & $\begin{array}{l}\text { Earned media } \\
\text { Affiliate marketing }\end{array}$ \\
\hline PPC & Job boards
\end{tabular}

Owned media

28

\section{Table 2.}

Distribution of digital marketing tools between types of media

\author{
Job boards
}

Online advertising

(paid display ads)

Direct messaging

(email marketing, mobile text messaging)

Source: Adapted from Stephen and Galak (2012)
Social media

(e.g. LinkedIn and Facebook company's pages)

Social media Online advertising

(word-of-mouth) (content marketing and posting on owned pages)

\section{Hypotheses development}

Hanssens and Pauwels (2016, p. 177) clarify effectiveness as being the "ability to reach the goal", and therefore overall recruitment effectiveness corresponds to the ability to hire the most-suited candidates. More specifically, this is achieved by influencing the target candidates' decision to apply for a job (Chapman et al., 2005; Maurer and Liu, 2007). Although a growing amount of literature is focussed on the effectiveness of online advertising in the marketing context (Goldfarb, 2014), Maurer and Liu (2007) believe that the literature is still failing to provide a theory-based understanding of how digital marketing contributes to the success of recruitment. Therefore, the goal of this study is to understand the impact of digital marketing on recruitment effectiveness, by focussing on how different tools and strategies influence candidates' decision to apply for a job, which culminates in the research question: "Do different digital marketing tools and strategies influence candidates' decisions during the recruitment process, and if so, how?".

Our objective is to add to the various hypotheses which have already been developed in the literature on human resources management and marketing fields, by carrying out a more knowledgeable research which contributes significantly to the current literature, while aiming to encounter findings which can be easily understood and can be used for managerial decisions.

Gowan and Lautenschlager (1993) define job choice as being a series of decisions made by a candidate to select the job and organisation for which to apply to. Hence, those individuals who start the job search process by carrying out an evaluation of the information that they were able to obtain from several recruitment sources, and then use this to base their first critical job search decision - whether to apply or not (Allen, Mahto, \& Otondo, 2007; Chapman et al., 2005; Fisher, Ilgen, \& Hoyer, 1979; Gowan \& Lautenschlager, 1993). Fisher et al. (1979) tend to ascertain that the source of the information is also crucial for the decision-making process. Taking this into consideration, and according to the premise that owned media is the less credible type of media (Baetzgen \& Tropp, 2015; O'Neil \& Eisenmann, 2017), the first hypothesis is as follows:

H1. When it comes to the candidates' decision to apply for a job, the information provided by the digital marketing tools owned by the company is less relevant than that provided by earned media. 
Fisher et al. (1979) believe that candidates assign different levels of credibility to the information that they gather through several sources, as the format of the presentation of the information can be as important as the information itself (Allen et al., 2013). Source credibility has two main dimensions: trustworthiness and expertise. Trustworthy sources are those which candidates perceive are not trying to persuade or influence them, and thus, sources which are independent of the company are generally seen to be more credible. On the other hand, candidates attribute more credibility to sources which they believe are knowledgeable about the subject (Fisher et al., 1979; Pornpitakpan, 2004).

Nevertheless, social media is shifting human interaction and the way that personal information is accessed, and consequently it influences how human resource managers recruit, screen and hire employees (Gibbs, MacDonald and MacKay, 2015). In addition, social media is gaining importance in the advertising of job openings and for the communication of information about the company (Chui et al., 2012; Klumper et al., 2016; Melanthiou, Pavlou, \& Constantinou, 2015) . SNS (e.g. LinkedIn, Facebook) are platforms where people create a personal profile and can connect with others and share information with a higher level of interactivity because of a more contagious content. Although SNS work the same way, they do not have the same context (Caers \& Castelyns, 2011; Madia, 2011; Nikolaou, 2014; Pisano et al., 2017; Richard, 2010). For instance, LinkedIn is a professional SNS and Facebook has a variety of goals - depending on its users (e.g. to connect with friends, to share hobbies, etc.). Furthermore, it is relevant to understand whether the SNS where candidates see job advertisements influence their perception of credibility, which leads to the next hypothesis:

H2. Job advertisements placed on LinkedIn are perceived to be more credible than those placed on Facebook.

In addition, Acarlar and Bilgiç (2013) suggest that the type of information in question influences the perception of credibility, and that certain characteristics, such as the amount, uniqueness and specificity, are all essential to influence the attraction of candidates to the organisation. Therefore, companies need to confront problems such as advertising intrusiveness, avoidance and consumer scepticism by offering useful and appealing content, which is also known as content marketing (Baetzgen \& Tropp, 2015). Because content marketing is a commonly used strategy, it is important to understand its influence on the recruitment process, which results in the third hypothesis:

H3. Content marketing has a positive influence on candidates' decision to apply for a job.

Furthermore, an organisation's reputation also influences candidates' attraction to the company, because it represents the affective evaluation made by candidates and their peers regarding the company's name, in comparison to other companies (Acarlar \& Bilgiç, 2013; Baum \& Kabst, 2014; Cable \& Graham, 2000). These beliefs can be connected to earned media - more specifically through WOM, as brand image, which helps to differentiate and create feelings of attachment in people's minds regarding a certain company, is developed and transmitted through WOM (Cable \& Yu, 2006; Cable, Aiman-Smith, \& Edwards, 2000; Collins, \& Stevens, 2002; Elving et al., 2013). Elving et al. (2013) indicate that companies are continuously working to become more attractive employers, which is linked to the way that certain characteristics of the company and the job are communicated in their own channels. Therefore, as earned media is seen to be more credible than owned media (Baetzgen \& Tropp, 2015; O'Neil \& Eisenmann, 2017), the proposed fourth hypothesis compares the
Influence of digital marketing 
EJMS

25,1

relevance of an organisation's reputation and the information transmitted by the company through their owned channels:

H4. Organisational reputation is more relevant for the decision to applying for a job than information transmitted through the digital marketing tools owned by the company.

\section{Method}

Research approach

As mentioned above, the existent literature still fails to provide a theory-based understanding of how digital marketing contributes to recruitment effectiveness (Maurer \& Liu, 2007). Therefore, the best approach for the research carried out for this study is qualitative research, because of its capabilities to collect and analyse open-ended answers which illustrate respondents' points of view regarding a topic about which little is known todate (Patton, 2002; Strauss \& Corbin, 1990).

More specifically, content analysis was selected, which is - "a research technique for making replicable and valid inferences from texts (or other meaningful matter) to the contexts of their use" (Kripperndorff, 2004, p.18), with the objective to provide new insights and increase the knowledge about this topic. Kripperndorff (2004) presents a framework which includes some essential conceptual components, namely,

- the body text - the starting point of the research;

- the research question - the research aim, which guides the study and also includes the hypotheses;

- the context - the conceptual environment selected by the researcher which gives sense to the body text;

- the analytical construct - which represents what is already known about the topic, to avoid overlapping;

- inferences - which are intended to answer the research question and hypotheses; and

- validating evidence - which assures the contribution to the existing literature.

Content analysis also allows the researcher to analyse relatively unstructured data better, with the aim to comprehend people's cognitive schemas, as well as the meaning and communicative roles which the data represents for individuals (Kripperndorff, 2004; Schreier, 2014; Weber, 1990).

\section{Data collection procedure and sample}

As stated above, the study focusses on the Portuguese market, with the objective to understand its specificities and provide managers with a more comprehensive view. The data was collected through a semi-structured one-to-one interview (see script in Table 3), which aimed to examine the research topic from the perspective of the interviewee and to understand how and why they have this particular perspective (King, 2004). The interview was also tested on two individuals to better adapt the script to new topics that emerged. Sampling was carried out by selecting the participants based on their knowledge and experience of the topic, together with snowball sampling, whereby new participants were contacted after asking a first selected group of respondents who to interview next (Kripperndorff, 2004; Patton, 2002). The requirements also included asking certain questions 
A brief introduction about the objectives of the interview and a contextualisation of the research. Request permission to record the interview

1. What are the digital marketing tools that you normally use when searching for a job?

a. Is there any other place where you find job offers, even if you are not actively looking for them?

b. From those, which ones do you find the most relevant for your decision to apply, or not?

c. What aspects/factors make them the most relevant?

2. Are you more willing to apply for a job position through a certain digital marketing tool?

a. Which one?

b. What are the reasons for choosing this/these ones?

3. Regarding social media, for you, what are the main differences between job openings advertisements on Facebook and LinkedIn?

a. Which ones do you find to be the most credible and relevant for your decision?

b. Why would you say this happens?

4. Which information is more important for your decision to apply for a job opening

a. Which digital marketing tool do you prefer to use to search for this information?

b. If the information is made available on a source which is controlled by the company (e.g. company's site), do you find it to be more or less credible?

c. Which information is more important for your decision: that which the company provides through their own channels and pages; or that which you access through a third party (whether it is your friends, connections, or pages not controlled by the company)?

5. Nowadays, some companies implement the strategy of content marketing - through producing and sharing valuable and interesting content that is not directly connected to their products or services, or in this case - the job opening (e.g. posts about the culture, their employees, the industry advances)

a. Does this make the company more attractive as a possible employer?

b. Does the fact that the company does this influence your decision to apply or not for the job opening?

6. What do you think is the role of the company's reputation in your decision to apply for a job opening?

a. Do think that reputation is more or less important than the information that the company provides about themselves and the job opening?

Table 3. Interview script

to ensure that the participants were currently employed or had looked for a job during the past year, and that they used LinkedIn for their job search.

The interviews were carried out during October, 2017, either face to face, via phone or by Skype. All participants were first introduced to the study and then asked for their permission to audio-record the interview. On average, the interviews lasted for half an hour, and the data was further transcribed verbatim to ensure its correct analysis. The study counts with 21 Portuguese participants, 11 of whom are women and 10 are men, with an average age of 22.8 years old, ranging from 21 to 27 . The interviewees came from a wide range of geographic locations, and either had a Bachelors $(28.6 \%)$ or a Masters degree $(71.4 \%)$. Additionally, $23.8 \%$ are currently in full-time study, $42.9 \%$ are currently in fulltime employment and $33.3 \%$ are working and studying simultaneously (for a more comprehensive view, consult Table 4).

\section{Data analysis}

The data from the transcribed interviews was the basis for the analysis, which was carried out by means of a coding process which followed certain steps, namely,

- initial coding - reading each transcript and attaching codes to interviews' extracts;

- coding dictionary - development of a list of codes, sub-codes linked based on their conceptual and logical similarity; and

- relationships - establishing and clarifying relationships among codes (Murphy, Klotz, \& Kreiner, 2017; Saldaña, 2009). 
EJMS

25,1

\begin{tabular}{|c|c|c|c|c|c|c|}
\hline $\begin{array}{l}\text { Interview } \\
\text { code }\end{array}$ & Age & Gender & Location & Habilitations & Course/degree & Occupation \\
\hline A & 22 & Female & Madeira & Masters & International Business & Student \\
\hline $\mathrm{B}$ & 22 & Male & Setúbal & Masters & Management & Student \\
\hline $\mathrm{C}$ & 24 & Male & Madeira & Masters & Management & $\begin{array}{l}\text { Business Optimisation \& } \\
\text { Online Payment }\end{array}$ \\
\hline $\mathrm{D}$ & 23 & Female & Beja & Bachelors & $\begin{array}{l}\text { Human Resources } \\
\text { Management }\end{array}$ & HR Technician \\
\hline $\mathrm{E}$ & 22 & Male & Coimbra & Masters & Computer Engineering & $\begin{array}{l}\text { Student \& worker - } \\
\text { Researcher }\end{array}$ \\
\hline $\mathrm{F}$ & 22 & Male & Lisboa & Masters & Computer Engineering & $\begin{array}{l}\text { Student \& worker - } \\
\text { Trainer }\end{array}$ \\
\hline G & 23 & Female & Coimbra & Masters & Digital Business & Student \\
\hline $\mathrm{H}$ & 25 & Male & Lisboa & Masters & $\begin{array}{l}\text { Industrial and } \\
\text { Organisational Economics }\end{array}$ & $\begin{array}{l}\text { Business Continuity and } \\
\text { Revenue Assurance } \\
\text { Department's Intern }\end{array}$ \\
\hline I & 21 & Female & Lisboa & Masters & Management & $\begin{array}{l}\text { Student \& worker - HR } \\
\text { Intern }\end{array}$ \\
\hline $\mathrm{J}$ & 23 & Female & Lisboa & Bachelors & Journalism & Journalist \\
\hline $\mathrm{K}$ & 27 & Female & Lisboa & Masters & ement & HR Technician \\
\hline $\mathrm{L}$ & 22 & Female & Lisboa & Masters & $\begin{array}{l}\text { Human Resources } \\
\text { Management and } \\
\text { Organisational Consulting }\end{array}$ & $\begin{array}{l}\text { Student \& worker - } \\
\text { People Management } \\
\text { Trainee }\end{array}$ \\
\hline M & 22 & Male & Lisboa & Bachelors & $\begin{array}{l}\text { Human Resources } \\
\text { Management }\end{array}$ & SAP Consultant \\
\hline $\mathrm{N}$ & 22 & Female & Beja & Masters & Psychology & $\begin{array}{l}\text { Student \& worker - } \\
\text { Cashier }\end{array}$ \\
\hline $\mathrm{O}$ & 22 & Female & Leiria & Masters & Digital Marketing & $\begin{array}{l}\text { Social Media Manager } \\
\text { Intern }\end{array}$ \\
\hline $\mathrm{P}$ & 24 & Male & Coimbra & Masters & International Business & $\begin{array}{l}\text { Assistant Branch } \\
\text { Manager }\end{array}$ \\
\hline Q & 25 & Male & Lisboa & Bachelors & $\begin{array}{l}\text { Human Resources } \\
\text { Management }\end{array}$ & $\begin{array}{l}\text { Talent Development } \\
\text { Intern }\end{array}$ \\
\hline $\mathrm{R}$ & 21 & Female & Lisboa & Bachel & Management & Student \\
\hline $\mathrm{S}$ & 23 & Male & Lisboa & Bachelors & Economics & Student \\
\hline $\mathrm{T}$ & 22 & Male & Lisboa & Masters & $\begin{array}{l}\text { Human Resources } \\
\text { Management and } \\
\text { Organisational Consulting }\end{array}$ & $\begin{array}{l}\text { Student \& worker - HR } \\
\text { Intern }\end{array}$ \\
\hline $\mathrm{U}$ & 22 & Female & Santarém & Masters & Accounting & $\begin{array}{l}\text { Student \& worker - Junior } \\
\text { Accountant }\end{array}$ \\
\hline
\end{tabular}

Table 4.

Interviewees' profile

This process was carried out using the MAXQDA software, to ensure a more structured approach. The coding dictionary can be seen in Table 5 .

\section{Results}

After the data was analysed, the coding dictionary was developed to systemise the findings and also participants' opinions and insights. Additionally, Figure 1 shows the research model overview and the relationships found between the major constructs. In this segment, the results are presented within each hypothesis to give a better outline of the ideas found, which are highlighted by quotes extracted from the interviews. 


\begin{tabular}{|c|c|c|c|}
\hline Code & Sub-codes & Frequency & IIIIUCHCe o1 \\
\hline \multicolumn{3}{|c|}{ 1. Digital marketing tools } & marketing \\
\hline \multicolumn{3}{|c|}{ 1.1. Digital marketing tools used to actively search for a job } & \\
\hline \multicolumn{3}{|c|}{ LinkedIn } & \\
\hline \multicolumn{2}{|r|}{ Job boards } & 16 & \\
\hline \multicolumn{2}{|r|}{ Company's website } & 15 & \\
\hline \multicolumn{2}{|r|}{ University's platform } & 13 & 33 \\
\hline \multicolumn{2}{|r|}{ Recruitment agencies } & 6 & 33 \\
\hline \multicolumn{2}{|r|}{ Facebook } & 1 & \\
\hline \multicolumn{4}{|c|}{ 1.2. Digital marketing tools used to passively search for a job } \\
\hline \multicolumn{2}{|r|}{ Notifications via email } & 29 & \\
\hline \multicolumn{2}{|r|}{ Direct offers - via email or a LinkedIn message } & 11 & \\
\hline \multicolumn{2}{|r|}{ Facebook groups } & 11 & \\
\hline \multicolumn{2}{|r|}{ Display an advertisement } & 8 & \\
\hline \multicolumn{4}{|c|}{ 1.3. Digital marketing tools which are more relevant for the decision to apply for a job } \\
\hline \multicolumn{4}{|c|}{ Digital marketing tools owned by the company } \\
\hline \multicolumn{2}{|r|}{ LinkedIn } & 17 & \\
\hline \multicolumn{2}{|r|}{ Company's website } & 10 & \\
\hline \\
\hline \multicolumn{4}{|c|}{$\begin{array}{l}\text { Reasons why they are the most relevant } \\
\text { i) More information }\end{array}$} \\
\hline & ii) More trustworthy and professional & 11 & \\
\hline & iii) More personalised and interactive & 5 & \\
\hline & iv) Direct contact with the recruiter & 2 & \\
\hline & v) Other tools redirect to them & 2 & \\
\hline & Digital marketing tools earned by the company & & \\
\hline & University's platform & 7 & \\
\hline & Job boards & 5 & \\
\hline & Reasons why they are the most relevant & & \\
\hline & i) Quantity of job offers & 6 & \\
\hline & ii) Discover new companies and job functions & 4 & \\
\hline & iii) Unaware of other platforms & 1 & \\
\hline 1.4 . & arketing tools used to apply for a job & & \\
\hline & Indifferent & 10 & \\
\hline & Digital marketing tools owned by the company & & \\
\hline & Company's website & 13 & \\
\hline & LinkedIn & 8 & \\
\hline & i) An easy-to-apply tool & 2 & \\
\hline & ii) Redirects to the company website or email address & 2 & \\
\hline & Reasons why they are the most relevant & & \\
\hline & i) More trustworthy and professional & 16 & \\
\hline & ii) Security & 1 & \\
\hline & Digital marketing tools earned by the company & & \\
\hline & University's platform & 2 & \\
\hline 1.5 . & tworking sites (SNS) & & \\
\hline & Facebook & & \\
\hline & Seen as not being credible when/because & & \\
\hline & i) More personal, less professional & 34 & \\
\hline & ii) Doubt the trustworthiness and credibility of offers & 11 & \\
\hline & iii) Lacks structure and was not built for this purpose & 5 & \\
\hline & iv) Has less information & 4 & \\
\hline & v) Groups with less specific audience & & \\
\hline & vi) Seen as a "last call", urgent action & 3 & \\
\hline & Seen as credible when & & \\
\hline & i) Groups with alumni or specific audience & 12 & \\
\hline & ii) Redirects to other tool/platform or email address & 4 & Table 5. \\
\hline & iii) Individuals know the people who advertise the job offer better & 3 & Coding book/ \\
\hline & & (continued) & dictionary \\
\hline
\end{tabular}




\begin{tabular}{llr}
\hline Code & Sub-codes & Frequency \\
\hline
\end{tabular}

LinkedIn

iv) Publication on the company's profile

Seen as more credible

i) More professional, serious and trustworthy

ii) More structured and has more information

2. Information that influences the decision to apply for a job

2.1. Job offer - function, requisites and type of contract

2.2. Company - industry, culture, vision, products and services

2.3. Salary

2.4. HR factors - training and turnover rates

2.5. Team members and qualifications

2.6. Information sources

Search engine

Digital marketing tools owned by the company

Company's website

LinkedIn

Seen as more credible

Seen as less credible

Doubts regarding trustworthiness of the information provided

Digital marketing tools earned by the company

Word-of-mouth

Someone with a current or former link to the company

Someone with no current or former link to the company

University's platform

Job boards

Seen as more credible

3. Content marketing

3.1. Positive influence on the decision to apply for a job $\quad 21$

Differentiation of the company 20

More information about the company, culture and team $\quad 12$

Has a role in the decision, but it is not an eliminatory factor $\quad 6$

More willingness to apply for a job in the industry, but not necessarily for the company 1

3.2. No influence on the decision to apply for a job

3.3. Positive impact on company's attractiveness

Shows the company's points of view and the willingness to start a conversation

3.4. No impact on the company's attractiveness

3.5. Company's industry influence on candidates' perception

3.6 Videos

4. Reputation

4.1. Sources of reputation

Current or former employees

Glassdoor and similar websites

Media

Clients

4.2. Has an influence on decision to apply for a job

Negative reputation

4.3. Does not have an influence on the decision to apply for a job

The case of small companies and startups

4.4. Reputation is more important than the information provided by the company

4.5 Reputation is less important than the information provided by the company

Table 5.

4.6. Reputation and information provided by the company are seen as being complementary 


\section{Information from owned versus earned media}

On the subject of digital marketing tools, participants were questioned about the relevance of these tools for their decision to apply for a job and their credibility. The results show that tools owned by the company seem to rank higher for both questions, which thus fails to support $H 1$. The data shows that owned media tools are seen to be more credible and that candidates regularly "search more on the company's website" or the company's LinkedIn page "to confirm the information" which they see on other platforms, as they seek tools "that can give more detailed information and that is trustworthy at the same time" (Interview H). Furthermore, owned media tools are also those for which more importance is attributed for the decision, as they are "generally more interactive and more representative of the brand" and can give a more personalised experience (Interview O). Nevertheless, some participants have shown doubts regarding the information provided by the company, because "it is the information they want to present, and not necessarily the truth" (Interview F). This represents the constant battle that candidates face because while, on one hand, they seek information from the company, on the other hand, they are also aware that such information can be embellished to persuade them to apply for the job.

Additionally, earned media tools can also be important for the decision, especially platforms provided by universities and job boards, as these offer a larger quantity of job openings and allow candidates to discover new companies and job functions. Besides, on universities' platforms, candidates feel that "companies that advertise there are expecting a profile" similar to theirs, which "increases the chances of being called for an interview" (Interview K). Moreover, these tools are also seen to be credible, mostly because of the importance that candidates attribute to WOM and the opinions of acquaintances who worked in the company, as this can provide "a more realistic view" of the offer, even though such an opinion needs to be weighted "because the subjectivity of third parties can also lead to a bad interpretation” (Interview E).

\section{Credibility: LinkedIn versus Facebook}

In general, all interviewees agreed that LinkedIn is the better choice in term of credibility, which supports H2. They feel that the platform "has a more formal environment than Facebook", because LinkedIn was built for that specific purpose and provides a structure to advertise job openings, which makes them "more informative and professional" (Interview D). Therefore, the credibility of LinkedIn can be explained by the fact that candidates perceived it to be a more professional and trustworthy platform. On the other hand, Facebook is generally seen to be less credible, because of its personal environment, which creates doubts regarding whether the job opening actually exists, or not, and also the intentions of the recruiters. In addition, because Facebook is a platform which was not built for the purpose of recruitment, it lacks structure and provides less information. However, advertisements on Facebook can be seen to be credible if they are posted on groups with alumni or specific audience and redirect the user to the company's website, LinkedIn page or

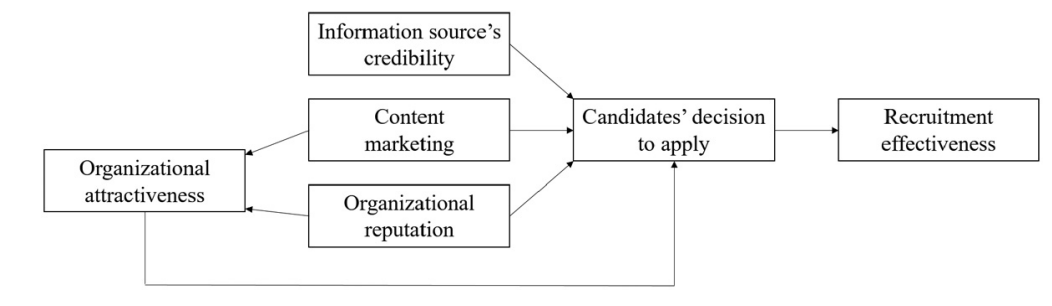

$$
\text { alumni or specific audience and redirect the user to the company's website, Linkedin page or }
$$

Influence of digital marketing

Figure 1. Research model overview 
EJMS 25,1

an email address, and also when candidates know personally the person whose Facebook account is advertising the job opportunity, or if they associate the person with a closer group, and therefore they are more comfortable to ask questions and ultimately to apply for the job in question.

\section{Influence of content marketing on recruitment effectiveness}

The collected data shows that content marketing has a positive influence on candidates' decision to apply for a job, which supports H3. Interviewees see content marketing as being a differentiation factor for companies, allowing them to provide more information about themselves and their culture, and "assuming that the job openings are identical" they seem to be "more inclined for a company which has that kind of strategy and initiative" because "it is a way to present itself to the exterior", which "gives a better perspective for whoever wants to apply" and "provides more realistic expectations" (Interview E). However, several participants also stated that although content marketing influences them, "it is not something essential" (Interview K) - i.e. it does not represent a major or eliminatory role in their decision. Furthermore, some individuals believe that the perception and influence of content marketing can differ from industry to industry, and job area to job area, because "there are several types of companies" and each must "understand if it makes sense for them have that concern, or not" (Interview J). There is also the risk of attracting candidates to the industry with the provided content, but not necessarily to the company itself.

Interviewees were also questioned about what information they seek to support their decision to apply for a job, and the answers focussed on the job offer itself, "the type of job, the functions" and the requisites (Interview A), the company and "the type of culture" (Interview B). In addition, some HR factors were highlighted, such as turnover rates and training, as well as the team members. Although most of the individuals who mentioned salary stated that it was not so important as to have to be present in the job advertisement, the truth is that salary was mentioned quite a lot.

\section{Reputation versus information provided through tools owned by the company}

The data suggests that reputation has a big influence on the candidates' decision, whether it is from what they hear through WOM, the media or other platforms such as Glassdoor, where employees can give their opinion, which supports $H 4$. Reputation is not only seen as being quite important, but it almost has the power to "make other things that might be questioned when assessing a company less relevant", such as the job function per se, or the touchpoint where candidates see the advertisement, and "make external sources (...) less relevant” (Interview O).

Individuals seem to be more willing to apply for a company that has a positive reputation, which has existed for several years and which has a more established presence in the market, as "by principle, reputation tells you that it is a good place to work, and that it could be a good school and a place to learn and develop as a person and as a professional" (Interview U). Regarding negative reputation, opinions seem to be split, with most interviewees stating they "would not like to work for a company with a negative reputation" (Interview A), especially in cases of corruption and other scandals, or the mistreatment of employees - all of which decreasing their willingness to apply for a job there. In contrast, negative reputation can be surpassed for some participants if the company in question is one where the candidate "really want(s) to work for and that matches the need at the moment" (Interview H), making them "willing to confirm" for themselves (Interview S).

Furthermore, most participants think that reputation "has more influence than what the company is actually saying" on their owned tools (Interview B). For reputation has more 
diversified sources, and participants "prefer to inform" themselves "through comments of people who work in the company" - because that information is "more credible and closer to the truth" (Interview C). Nevertheless, it is also relevant to state that some interviewees do not feel that reputation has an influence on the decision to apply, especially in the case of smaller companies or startups, as these are not sufficiently established to have created a reputation for themselves.

Discussion

The goal of this study is to understand the influence of digital marketing on recruitment effectiveness and contribute to the existent literature on the subject with new findings or a further confirmation of established ideas. To start with, the findings of this study challenge the conventional idea that owned media is the least credible type of media, which has been defended by several authors (Baetzgen and Tropp, 2015; O'Neil \& Eisenmann, 2017). Our results show that in the recruitment environment, owned media tools are considered to be more credible, which is an essential characteristic for sources and their influence on how information is processed (Van Hoye \& Lievens, 2005). Furthermore, owned media tools are seen to be more capable of providing detailed and relevant information, which makes them the most important type of sources to support the decision to apply for a job. Company's websites and LinkedIn page are the most preferred and the most frequently referred tools, with candidates even associating certain traits about the company and its culture to how the information is exposed on these channels.

Nonetheless, for companies, the question is no longer whether they should join the digital conversation or not, for the pressure to adopt an online presence is so significant that it is impossible to ignore it. The adoption of this strategy establishes ground for mutually satisfying long-term relationships with the audience - which in this case of this study are potential candidates. According to Tiago and Veríssimo (2014), Portuguese companies embrace digital presence mainly because of external competitive pressure and internal efficiency, with the objective to build their brand, improve knowledge and improve communication flows.

Regarding social media, not surprisingly, LinkedIn was established to be more credible than Facebook, because of its trustworthiness and expertise (Fisher et al., 1979; Pornpitakpan, 2004), as it is a platform which is specifically structured for that purpose and it is more professional and informative.

This study shows that content marketing makes the company more attractive as a potential employer and enables it to differentiate itself from competitors, which has a positive influence on the decision to apply for a job. Moreover, content marketing also allows candidates to gather more information to support their decision. Research shows that a larger amount of information increases the perception of credibility and results in a greater possibility of applying for a job. Furthermore, the more specific the message, the greater the interest in the job opening and the more attention candidates give to the message - which can result in a better person-organisation fit (Allen et al., 2007; Breaugh, 2013). Lievens and HighHouse (2003) defend that candidates' initial attraction to a company can be explained by instrumental attributes, i.e. concrete and factual attributes regarding a job and the company (e.g. salary), as well as symbolic attributes, i.e. subjective and intangible attributes that describe a job or the company (e.g. being innovative). Nevertheless, Allen et al. (2007) defend that questions remain unanswered about the usefulness of the information that is collected throughout the different stages of the job search.

Finally, the study confirms that reputation is a major part of the decision process, as the image that candidates create of the company deeply influences their perspective about what

Influence of digital marketing 
EJMS

25,1

the company says and how they react to it - whether this image is created through their own experiences, or through the experiences and opinions of others. Ultimately, this image has an impact on their decision to apply for a job (Cable \& Graham, 2000; DiStaso \& Brown, 2015). The study also suggests that reputation is more important than what the company actually says, as candidates have doubts whether the information the company provides is entirely real and accordingly seek other sources on which to base their decisions. WOM is especially relevant in this new digital era and it represents an interpersonal communication, that is independent of the company and which can transmit positive or negative information (Van Hoye et al., 2016). Furthermore, Collins and Stevens (2002) found that positive WOM has a strong effect on organisational attractiveness, and the study of Van Hoye and Lievens (2005) established that negative WOM has an even larger impact than positive WOM. This is perhaps the biggest fear of organisations in this digital and social world, as information can spread so quickly and get out of control so easily, that it can either ruin or build a company's reputation in a few tweets or Facebook publications (Kluemper, Mitra, \& Wang, 2016; Malita, Badescu, I., \& Dabu, 2010).

\section{Theoretical contributions}

The results show that owned media is a credible source of information in the recruitment context, challenging the conventional idea that refers to the contrary (Baetzgen \& Tropp, 2015; O'Neil \& Eisenmann, 2017). The findings even suggest some reasons why owned tools are more relevant for the decision to apply for a job, namely, because they provide more information, they are more trustworthy, professional, personalised and interactive; they provide the opportunity to have a direct contact with the recruiter; and also because other sources redirect to them (especially earned tools, such as job boards and universities' platforms).

In spite of this finding, possibly, our greatest contribution to literature on this subject is the identification of the parameters which can lead to more credible job advertisements on Facebook, namely, the use of groups with alumni or a specific audience; redirection to the company's website, LinkedIn page or email address; familiarity with the recruiter; and the possibility to ask questions in an informal context (Fatkin \& Lansdwon, 2017).

With regard to information, the study presents the following categories of information which have an influence on candidates' decision to apply for a job: the job offer itself and its functions, requisites and type of contract; the company, the industry where it works and its culture, vision, products and services; the salary, where its mere reference in the job advertisement is seen to be a plus for the respondents; human resources factors, such as turnover rates and the expected training; and, finally, the team members and their qualifications.

The findings also suggest that content marketing has a positive influence on the decision to apply for a job, as it provides further information about the company and its culture and the team. However, although it has a role in the decision to apply for a job, content marketing is not seen to be the most relevant element. Furthermore, interviewees also mention that they can be more willing to apply for a job in the sector, and not necessarily for the company itself.

Finally, in relation to small companies and startups, our study shows that reputation does not have a decisive influence on the decision to apply for a job in these companies, as many of the companies in question had not had the time or the opportunity to develop such a long-term attribute.

\section{Practical implications}

The results show that it is essential that managers, especially those responsible for recruitment and marketing, implement the necessary strategies to tackle emerging 
challenges. First, managers should implement an integrated marketing communication (IMC) strategy - i.e. a communication strategy which integrates different tools to communicate the recruitment message effectively to the targeted audience, combining traditional and new media, whilst depending heavily on data (Batra \& Keller, 2016; Luxton, Reid, \& Mavondo, 2015; Madia, 2011). If managers advertise job openings in all the available platforms, and convey a clear message, which is adapted to the audience for each one, then they will be able to reach even more potential candidates and retain their attention, which consequently results in a larger and more appropriate pool of candidates (Luxton et al., 2015). To successfully implement an IMC strategy, managers need to consider the following factors: consistency - and thus reinforce a persuasive message through the means of different tools and touchpoints; complementarity - using leverage on each tool's strength; and cross-effects - as the communication effects from a previous touchpoint can improve the receptiveness of the information from others (Batra \& Keller, 2016).

Palos-Sanchez, Saura and Debasa (2018) also highlight the importance of emerging mobile technologies, which will have a significant impact on how digital marketing will work in the future, as they offer ease of use and accessibility and affect the effectiveness of conversion. Mobile marketing is fueled by the advancements in mobile technologies and their technical benefits, which currently are not being fully exploited, because of the lack of experience and expertise among professionals (Smutkupt, Krairit, \& Esichaikul, 2010).

Our research highlights candidates' need for valid information and its impact on their decision, and thus, nowadays, companies need to do more than just advertise the job position when recruiting, and they need to promote their brand and corporate image to convince candidates that they are the best employer - through content marketing and storytelling (Allen et al., 2013; Blackman, 2006; Elving et al., 2013; Fisher et al., 1979). Blackman (2006) explains that a recruitment advertisement is a form of persuasive communication, which needs to attract readers' attention and be able to stand out from other advertisements, to then create an interest to know more, building a relationship between the candidate and the company and enhancing the possibility of applying for the job in question. Several aspects make an advertisement better, namely, thought-provoking and appealing headlines; media richness; the structure and design of the advertisement; descriptive information; and interactivity (Blackman, 2006; Baum \& Kabst, 2014; Cable et al., 2000; Cable \& Yu, 2006; Frasca \& Edwards, 2017; Howardson \& Behrend, 2014; Maurer \& Liu, 2007). Furthermore, a more targeted approach to advertisements would be welcome, which can be achieved by creating specific content for the different target groups of candidates (e.g. management students, engineering students). A more focussed approach has been proven to be more engaging and effective (Pulizzi, 2012).

Additionally, social media usage will continue to grow as it gains more and more importance on individuals' life, shaping how they receive and process information. As a result, companies must adapt quickly to answer these new needs, by changing their communication approach and by engaging their targets in online conversations through SNS (Dijkmans, Kerkhof, \& Beukeboom, 2015). Although most companies are becoming aware of this need and its advantages - namely, the enhanced trustworthiness, positive brand attitude and increased commitment - they still find it hard to implement a winning strategy, because they lack expertise and are unfamiliar with this environment and are still afraid of the costs involved or the negative reputation that can arise from a lack of control, with many remaining tied to traditional approaches (Chui et al., 2012; Dijkmans et al., 2015; Kluemper et al., 2016; Malita et al., 2010; Melanthiou et al., 2015).

In addition, it is extremely important to place all the information on owned media tools, because candidates like to confirm if the job opening is real on the company's website or its
Influence of digital marketing 
EJMS

25,1

LinkedIn page. Advertising on universities' platforms is also essential, as individuals feel that such an advertisement is more tailored to them and that the company is looking for someone with a profile similar to theirs - which makes it easier for them to apply for the job or to search more. Furthermore, managers must be careful regarding content marketing, to ensure that it is used to attract candidates not only for the industry, but also for the company itself - by providing useful and valuable content regarding both topics and through signalling instrumental and symbolic attributes.

Finally, and perhaps the biggest challenge is the need to strike a balance between the control of the information by the company and the involvement and engagement of third parties, which is especially relevant in the current digital era, where individuals expect to be part of the conversation. Indeed, the capacity to generate and leverage insights through big data is a must-have for companies, and managers should put in place established processes to capture, storage, transfer and analyse all the data throughout the entire customer journey, to optimise advertising, content and the required budgets (Leeflang, Verhoef, Dahlström, \& Freundt, 2014).

\section{Limitations and future research directions}

Naturally, this study has limitations which need to be acknowledged. First, the use of mainly Portuguese students could decrease the possibility of generalisation and external validity (Acarlar \& Bilgiç, 2013; Silvertzen et al., 2013). Additionally, the sample needs to be larger, to collect more insights about the subject. Second, in the content analysis, some topics were left out for the sake of the answers for the hypotheses, and therefore it would be interesting to follow up on certain topics which emerged, but were too dissimilar to be included (e.g. perceptions about video content). This would provide a more in-depth understanding of sub-topics which emerged during the interviews, and would thus result in a more inclusive study.

Based on the discussion and the limitations of this study, there is room to improve in future research. First, it would be interesting to carry out a cross-area comparison study with students, to understand whether diverse areas see digital marketing strategies differently. Second, a further validation of the parameters found that seem to make Facebook advertisements more credible would also be a valuable contribution. Third, a topic that emerged is the importance and role of review platforms for the recruitment process, such as Glassdoor, which help understand how candidates use them and whether they find review platforms useful and credible and if the use of such platforms impacts recruitment effectiveness, as research already has focussed on review platforms as being an integral part of the customer journey in the broad marketing sense (Kluemper et al., 2016; Leeflang et al., 2014).

Fourth, the influence of content marketing on the person-organisation fit perception has room for further research, because candidates seek to understand if the attributes and values of the company match with their own, and, as our research shows, content marketing is a way for job seekers to obtain more information about the company in question (Cable and Judge, 1996). Furthermore, because the results show that content marketing is not a preponderant factor, it would be relevant to understand its weight in the decision to apply for a job, how it changes from context to context (e.g. depending on the company's reputation) and which type of content is more influential.

Finally, future research could focus on the impact of social media on brand reputation, to understand its role in managing brand reputation and to provide more practical insights for managers (Leeflang et al., 2014). 


\section{Conclusion}

The main goal of this study is to understand how digital marketing influences candidates' decision to apply for a job. The results show that candidates consider information from owned media tools to be more credible and relevant for their decision, and that they look for tools which are more trustworthy and specialised, such as LinkedIn, or the company's website. Additionally, content marketing seems to have a positive impact on the decision to apply for a job, as it provides applicants with more insights about the company, its culture and the industry itself. Finally, reputation still represents a major part of the decision process, which is a challenge for companies in this information-driven age. The adaption to the digital era and the new consumer's mindset is still a challenge for most companies; however, those who are willing to dare and take risks first will be those who succeed. Companies should definitely adopt an IMC strategy as a means to effectively communicate to the target audience and promote brand and corporate image through content marketing and storytelling. In sum, companies should strive to convince their candidates that they are the best employers. Furthermore, on account of the rapid development of technology, it is also relevant for companies to pay close attention to emerging trends, such as mobile marketing.

\section{References}

Acarlar, G., \& Bilgiç, R. (2013). Factors influencing applicant willingness to apply for the advertised job opening: the mediational role of credibility, satisfaction and attraction. The International Journal of Human Resource Management, 24,(1), 50-77.

Allen, D. (2013). Reactions to recruitment web sites: Visual and verbal attention, attraction, and intentions to persue employment. Journal of Business and Psychology, 28(3), 263-285.

Allen, D., Mahto, R., \& Otondo, R. (2007). Web-based recruitment: Effects of information, organizational brand, and attitudes toward a web site on applicant attraction. Journal of Applied Psychology, Vol. 92, No. (6), 1696-1708.

Baetzgen, A., \& Tropp, J. (2015). How can brand-owned media be managed? Exploring the managerial success factors of the new interrelation between brands and media. International Journal on Media Management, Vol. 17 No. (3), 135-155.

Baltes, L. (2015). Content marketing - The fundamental tool of digital marketing. Bulletin of the Transilvania University of Brasov - Economic Sciences, 8(2), 111-118.

Batra, R., \& Keller, K. (2016). Integrated marketing communications: New findings, new lessons, and new ideas. Journal of Marketing, 80(6), 122-145.

Baum, M., \& Kabst, R. (2014). The effectiveness of recruitment advertisements and recruitment websites: indirect and interactive effects on applicant attraction. Human Resource Management, 53(3), 353-378.

Blackman, A. (2006). Graduating students' respondes to recruitment advertisements. Journal of Business Communication,43(4), 367-388.

Bonchek, M. (2014). Making sense of owned media. Harvard Business Review, 10, 2-4.

Breaugh, J. (2013). Employee recruitment. Annual Review of Psychology, 64(1), 389-416.

Breaugh, J. (2016). Talent acquisition: a guide to understanding and managing the recruitment process, VT: SHRM Foundation.

Cable, D., \& Graham, M. (2000). The determinants of job seekers' reputation perceptions. Journal of Organizational Behavior, 21(8), 929-947.

Cable, D., \& Judge, T. (1996). Person-organization fit, job choice decisions, and organizational entry. Organizational Behavior and Human Decision Processes, 67(3), 294-311.

Influence of digital marketing 
EJMS 25,1

Cable, D., \& Yu, K. (2006). Managing job seekers' organizational image beliefs: the role of media richness and media credibility. Journal of Applied Psychology, 91(4), 828-840.

Cable, D., Aiman-Smith, L., \& Edwards, J. (2000). The sources and accuracy of job applicant's beliefs about organizational culture. Academy of Management Journal, 43(6), 1076-1085.

Caers, V., \& Castelyns, R. (2011). LinkedIn and facebook in Belgium: the influences and biases of social network sites in recruitment and selection procedures. Social Science Computer Review, Vol. 29 No. (4), 437-448.

Cappelli, P. (2001). Making the most of on-line recruiting. Harvard Business Review, 79(3), 139-146.

Chapman, D. (2005). Applicant attraction to organizations and job choice: A meta-analytic review of the correlates of recruiting outcomes. Journal of Applied Psychology, 90 (5), 928-944.

Chui, M. (2012). The social economy: unlocking value and productivity through social technologies, McKinsey Global Institute.

Collins, C., \& Stevens, C. (2002). The relationship between early recruitment-related activities and the applicant decision of new labor-market entrants: A brand equity approach to recruitment. Journal of Applied Psychology, 87(6), 1121-1133.

Dijkmans, C., Kerkhof, P., \& Beukeboom, C. (2015). A stage to engage: social media use and corporate reputation. Tourism Management, 47, 58-67.

DiStaso, M., \& Brown, B. (2015). From owned to earned media: An analysis of corporate efforts about being on fortune lists. Communication Research Reports, 32(3), 191-198.

Elving, W., Westhoff, J., Meeusen, K., \& Schoonderbeek, J. (2013). The war for talent? The relevance of employer branding in job advertisements for becoming an employer of choice. Journal of Brand Management, 20(5), 355-373.

Fisher, C., Ilgen, D., \& Hoyer, W. (1979). Source credibility, information favorability, and job offer acceptance. Academy of Management Journal, Vol. 22 No. (1), 94-103.

Frasca, K., \& Edwards, M. (2017). Web-based corporate, social and video recruitment media: Effects of media richness and source credibility on organizational attraction. International Journal of Selection and Assessment, 5, 125-137.

Gibbs, C., MacDonald, F., \& MacKay, K. (2015). Social media usage in hotel human resources: Recruitment, hiring and communication. International Journal of Contemporary Hospitality Management, 27(2), 170-184.

Goldfarb, A. (2014). What is different about online advertising? Review of Industrial Organization, 44(2), 115-129.

Gowan, M., \& Lautenschlager, G. (1993). Corporate image, recruitment image, and initial job choice decisions. Academy of Management Journal, 36(2), 414-427.

Hanssens, D., \& Pauwels, K. (2016). Demonstrating the value of marketing. Journal of Marketing, 80(6), 173-190.

Howardson, G., \& Behrend, T. (2014). Using the internet to recruit employees: comparing the effects of usability expectations and objective technological characteristics on internet recruitment outcomes. Computers in Human Behavior, 31, 334-342.

Johnson, S. (2014). Attracting the best and the brightest: the changing face of recruiting for CPA firms. CPA Practice Management Forum, 14-15.

Johnson, R., \& Gueutal, H. (2011). Transforming HR through technology: the use of e-HRand HRIS in organizations, VT: SHRM Foundation.

Judy, R. (1999). Labor forecast: gray skies, worker drought continues. HR Maganize, 44, 18-26.

Kannan, P., \& Li, H. (2017). Digital marketing: a framework, review and research agenda. International Journal of Research in Marketing, 34(1), $22-45$.

Kee, A., \& Yazdanifard, R. (2015). The review of content marketing as A new trend in marketing practices. International Journal of Management, Accounting and Economics, 2(9), 1055-1064. 
King, N. (2004). Using interviews in qualitative research. Essential guide to qualitative methods in organizational research, pp. 11-22. London: SAGE Publications.

Kluemper, D., Mitra, A., \& Wang, S. (2016). Social media use in HRM. Research in Personnel and Human Resources Management, 34, 153-207.

Kripperndorff, K. (2004). Content analysis: an introduction to its methodology, 2nd ed., London: Sage.

Ladkin, A., \& Buhalis, D. (2016). Online and social media recruitment: hospitality employer and prospective employee considerations. International Journal of Contemporary Hospitality Management, 28 (2), 327-345.

Leeflang, P., Verhoef, P., Dahlström, P., \& Freundt, T. (2014). Challenges and solutions for marketing in a digital era. European Management Journal, 32(1), 1-12.

Lievens, F., \& HighHouse, S. (2003). The relation of instrumental and symbolic attributes to a company's attractiveness as an employer. Personnel Psychology, 56(1), 75-102.

Luxton, S., Reid, M., \& Mavondo, F. (2015). Integrated marketing communication capability and brand performance. Journal of Advertising,44 (1), 37-46.

Madia, S. A. (2011). Best practices for using social media as a recruitment strategy. Strategic HR Review, 10 (6), 19-24.

Malita, L., Badescu, I., \& Dabu, R. (2010). Culture tips on online job searching. Procedia - Social and Behavioral Sciences, 2(2), 3070-3074.

Maurer, S., \& Liu, Y. (2007). Developing effective e-recruiting websites: insights for managers from marketers. Business Horizons, 50(4), 305-314.

Melanthiou, Y., Pavlou, F., \& Constantinou, E. (2015). The use of social network sites as an erecruitment tool. Journal of Transnational Management, 20 (1), 31-49.

Murphy, C., Klotz, A., \& Kreiner, G. (2017). Blue skies and black boxes: the promise (and practice) of grounded theory in human resource management research. Human Resource Management Review, 27(2), 291-305.

Nikolau, I. (2014). Social networking web sites in job search and employee recruitment. International Journal of Selection and Assessment, 22 (2), 179-189.

O’Neil, J., \& Eisenmann, M. (2017). An examination of how source classification impacts credibility and consumer behavior. Public Relations Review, 43, 278-292.

Palos-Sanchez, P., Saura, J., \& Debasa, F. (2018). The influence of social networks on the development of recruitment actions that favor user interface design and conversions in mobile applications powerd by linked data. Mobile Information Systems, 2018, 1-11. Article ID 5047017.

Paolini, S., \& Duguay, E. (2012). Towards "people 2.0”: adding digital drivers to the people management, Capgemini Consulting.

Patton, M. (2002). Qualitative research \& evaluation methods, 3rd ed., CA: Sage Publications.

Pisano, S., Lepore, L., \& Lamgoglia, R. (2017). Corporate disclosure of human capital via linkedin and ownership structure: An empirical analysis of european companies. Journal of Intellectual Capital, 18 (1), 102-127.

Pornpitakpan, C. (2004). The persuasiveness of source credibility: a critical review of five decades' evidence. Journal of Applied Social Psychology, 34 (2), 243-281.

Puncheva-Michelotti, P., Hudson, S., \& Jin, G. (2018). Employer branding and CSR communication in online recruitment advertising. Business Horizons, 61(4), 643-651.

Pulizzi, J. (2012). The rise of stortytelling as the new marketing. Publishing Research Quarterly, 28 (2), 116-123.

Rajan, A. (2015). A vision of future recruitment. Human Capital, 19 (4), 30-32.

Richard, D. (2010). Getting social with recruitment. Strategic HR Review, 9 (6), 11-15.

Roberts, G. (1997). Recruitment and selection: a competency approach, London: CIPD Publishing.

Influence of digital marketing

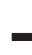


EJMS

25,1

Rowley, J. (2008). Understanding digital content marketing. Journal of Marketing Management, 24(5-6), $517-540$.

Saldaña, J. (2009). The coding manual for qualitative researchers, London: Sage.

Schreier, M. (2014). Qualitative content analysis. The SAGE handbook of qualitative data analysis (170-183). London: Sage.

Singh, P., \& Finn, D. (2003). The effects of information technology on recruitment. Journal of Labor Research, 24 (3), 395-408.

Sivertzen, A., Nilsen, E., \& Olafsen, A. (2013). Employer branding: employer attractiveness and the use of social media. Journal of Product \& Brand Management, 22 (7), 473-483.

Smutkupt, P., Krairit, D., \& Esichaikul, V. (2010). Mobile marketing: implications for marketing strategies. International Journal of Mobile Marketing, 5 (2), 126-139.

Spitzer, B., Vernet, A., Soderstrom, C., \& Nambiar, R. (2013). Using digital tools to unlock HR's true potential, Capgemini Consulting.

Stephen, A., \& Galak, J. (2012). The effects of traditional and social earned media on sales: a study of a microlending marketplace. Journal of Marketing Research, 49(5), 624-639.

Strauss, A., \& Corbin, J. (1990). Basics of qualitative research: grounded theory procedures and technique, CA: Sage Publications.

Tiago, M., \& Veríssimo, J. (2014). Digital marketing and social media: why bother? Business Horizons, 57(6), 703-708.

Van Hoye, G., \& Lievens, F. (2005). Recruitment-related information sources and organizational attractiveness: can something be done about negative publicity? International Journal of Selection and Assessment, 13 (3), 179-187.

Van Hoye, G., Weijters, B., Lievens, F., \& Stockman, S. (2016). Social influences in recruitment: when is word-of-mouth most effective? International Journal of Selection and Assessment, 24 (1), 42-53.

Weber, R. (1990). Basic content analysis, 2nd ed., Sage: Newbury Park.

Yasmin, A., Tasneem, S., \& Fatema, K. (2015). Effectiveness of digital marketing in the challenging age: An empirical study. The International Journal of Management Science and Business Administration, 1(5), 69-80.

\section{Corresponding author}

Dalvia Rodrigues can be contacted at: dalviarodrigues@gmail.com

For instructions on how to order reprints of this article, please visit our website:

www.emeraldgrouppublishing.com/licensing/reprints.htm

Or contact us for further details: permissions@emeraldinsight.com 